EXTENDED REPORT

\title{
The Auckland Cataract Study: 2 year postoperative assessment of aspects of clinical, visual, corneal topographic and satisfaction outcomes
}

\section{A M Thompson, N Sachdev, T Wong, A F Riley, C N Grupcheva, C N McGhee}

Aim: To assess clinical, visual, computerised corneal topographic, and subjective satisfaction with visual acuity, in a cohort of subjects 2 years after phacoemulsification surgery in a public hospital in New Zealand.

Methods: Prospective study of a representative sample of 97 subjects (20\%) randomly selected from 480 subjects in the original Auckland Cataract Study (ACS) cohort. The clinical assessment protocol was identical to the ACS and included an extensive questionnaire to enable direct comparisons to be made between the two groups.

Results: The study population was predominantly female (66\%) with a mean age of 76.3 (SD 9.9) years. New systemic and ocular disease affected $18.4 \%$ and $10.3 \%$ of subjects respectively, and $10.3 \%$ required referral to either a general practitioner $(2.1 \%)$ or ophthalmologist $(8.2 \%)$. Mean best spectacle corrected visual acuity (BSCVA) was 0.2 (0.2) logMAR units (6/9 Snellen equivalent), with mean spherical equivalent -0.37 (1.01) dioptres (D) and astigmatism - $1.07(0.70)$ D 2 years postoperatively, compared to mean BSCVA 0.1 (0.2) logMAR units (6/7.5 Snellen equivalent), spherical equivalent -0.59 (1.07) $D$,

See end of article for authors' affiliations

Correspondence to: Professor C N J McGhee, Department of

Ophthalmology, University of Auckland, Private Bag 92019, Auckland 1001, New Zealand; c.mcghee@ auckland.ac.nz

Accepted for publication 8 December 2003 and astigmatism -1.14 (0.77) D 4 weeks after surgery. $94.9 \%$ of subjects retained a BSCVA of $6 / 12$ or better, irrespective of pre-existing ocular disease. The overall posterior capsule opacification (PCO) rate was $20.4 \%$ and this was visually insignificant in all but $3.1 \%$ of eyes that had already undergone Nd:YAG posterior capsulotomy. Orbscan II elevation technology demonstrated corneal stability 2 years after uncomplicated phacoemulsification. Although corneal astigmatism was eliminated in approximately half of the subjects 1 month postoperatively, astigmatism showed a tendency to regress towards the preoperative level with local corneal thickening at the site of incision 2 years after cataract surgery. Of fellow eyes, $61.2 \%$ had undergone cataract surgery. Overall, $75.3 \%$ of subjects were moderately to very satisfied with their current level of visual acuity.

Conclusion: Two years after cataract surgery subjects are generally satisfied with their current level of vision and distance BSCVA is 6/12 or better in the majority of eyes. Although only a minority of eyes develop sufficient PCO to require capsulotomy $10.3 \%$ of eyes develop new vision threatening ocular pathology.

\begin{abstract}
C ataract surgery is a successful and increasingly frequently performed ophthalmic surgical procedure to reverse the visual and functional disability caused by cataract. In an effort to establish surgical, clinical, topographic, and functional outcomes of subjects undergoing contemporary cataract surgery, the Auckland Cataract Study (ACS) prospectively assessed a large cohort of affected subjects in a major New Zealand public hospital during the year 2000. ${ }^{12}$ Subjects underwent extensive ophthalmic assessment 1 day, 4 weeks, and 3 months after surgery; however, they were not routinely followed beyond this time unless complications were previously identified. Other recent studies have evaluated various subjective, clinical, and surgical outcomes at differing times post-cataract surgery, ${ }^{3-5}$ including satisfaction and degree of corneal astigmatism. However, questions still remain as to whether improved visual acuity remains stable after cataract surgery, or whether subjects are satisfied with their visual and functional outcomes in the longer term. The purpose of this study was to identify the clinical and visual outcomes of subjects 2 years after cataract surgery in a public hospital in New Zealand.
\end{abstract}

\section{SUBJECTS AND METHODS}

In all, 155 subjects $(32.3 \%)$ were identified in a random fashion from the original ACS cohort $(n=480)$ and invited by letter to participate in a 2 year follow up assessment. It was stipulated that participation in the study was voluntary and would not affect the individual's right to ongoing or future treatment. Telephone contact was made with subjects who failed to respond to the initial letter of invitation. Medical records were consulted for any deaths among the selected group and related data were excluded from further evaluation. Sixty three per cent $(n=97)$ of the subjects contacted agreed to participate in this 2 year follow up assessment.

Subjects were subsequently examined between June and August 2002 inclusive. This prospective study comprised 98 eyes of 97 subjects (20.2\%), all of whom underwent cataract surgery with intraocular lens (IOL) implantation during the year 2000 at Auckland Public Hospital as part of the ACS. Surgeons who performed the cataract surgery included 17 consultants, three fellows, and six registrars, with $98 \%$ of procedures performed using small incision phacoemulsification, $1 \%$ being extracapsular cataract extraction (ECCE) and $1 \%$ conversion of phacoemulsification to ECCE. Local medical

Abbreviations: ACS, Auckland Cataract Study; BSCVA, best spectacle corrected visual acuity; ECCE, extracapsular cataract extraction; $I O L$, intraocular lens; logMAR, logarithm of the minimum angle of resolution; PCO, posterior capsule opacification; UAVA, unaided visual acuity 
ethics committee approval was obtained for all aspects of this project.

Subjects were examined using the protocol developed for the ACS. ${ }^{1}$ Any new ophthalmic or medical history in the past 2 years was obtained from each subject by a single examiner (AMT) who also conducted all ophthalmic examinations. Visual acuity was recorded for each eye using a 4 metre standardised logarithm of the minimum angle of resolution $(\log M A R)$ chart. Each subject underwent a full ophthalmic examination that included anterior segment slit lamp biomicroscopy, autokeratorefractometry (KR 8100, Topcon), computer assisted elevation topography (Orbscan II, Bausch and Lomb), dilated funduscopy, and measurement of intraocular pressure (IOP) (Tonopen). The presence of coexisting ocular disease was noted and compared to the preoperative evaluation. The type, model, and manufacturer of the implanted IOL were ascertained from the subject's operative record. Although the study was specifically aimed at review of the eyes operated under the ACS protocol, for clinical completeness both eyes of all subjects were examined.

Following calibration, slit scanning elevation corneal topography (Orbscan II) was performed preoperatively, 1 month, and 2 years after phacoemulsification. Subsequently, axial keratometric power maps, with 1.0 dioptre (D) incremental colour steps, were independently classified by two ophthalmologists (AMT, CNG) using the same protocol utilised in the ACS. ${ }^{167}$ Difference axial keratometric maps were used to assess the surgical effect (l month postoperative map minus preoperative map) and postoperative stability (2 year postoperative map minus 1 month postoperative map and 2 year postoperative minus preoperative map) and were analysed using proprietary software (Version 3.12). Fourth dimensional pachymetry analysis was performed as previously described, ${ }^{8}$ using 12 circular $\left(12.57 \mathrm{~mm}^{2}\right)$ areas located in 12 equidistant meridia $4 \mathrm{~mm}$ from the optical axis, and an additional single area of $12.57 \mathrm{~mm}^{2}$ centred on the optical axis of the device. For each cornea the area corresponding to the incision site was analysed separately. Any discrepancy in the classification and evaluation of the maps was discussed between the examiners and a consensus reached.

Posterior capsule opacification (PCO) was evaluated following instillation of a topical mydriatic (tropicamide $1.0 \%$, Alcon Laboratories) in order to allow observation of at least the central $5.0 \mathrm{~mm}$ of the posterior capsule. PCO density was clinically graded from 0 to 4 according to a clinical classification based on the Evaluation of Posterior Capsule Opacification (EPCO) medical system software. ${ }^{10}$ Eyes exhibiting grades 3 and 4 PCO, involving the central posterior capsule, were offered neodymium:YAG (Nd:YAG) posterior capsulotomy. Cases of intraoperative posterior capsule rupture were identified and excluded from the PCO and Nd:YAG posterior capsulotomy analyses.

Each subject completed an extensive self administered subjective questionnaire modified from the VF-14 cataract questionnaire. ${ }^{11}$ This was mailed to subjects before the date of examination and was an identical questionnaire to one completed by these subjects postoperatively as part of the ACS assessment. Subjects in the two groups completed questionnaires a mean of 3.6 (SD 1.2) months and 25.6 (SD 1.7) months postoperatively. The same questionnaire was used to enable direct comparisons to be made between the two groups.

Statistical analyses were performed using the Statistical Package for the Social Sciences (SPSS). Normally distributed difference data were analysed using paired Student's $t$ tests. Wilcoxon unpaired tests were used for data that was not normally distributed, and $\chi^{2}$ for categorical data. Multivariate analysis was employed to estimate the effect of several variables on final visual acuity. A 5\% significance level was maintained throughout these analyses, and all tests were two tailed.

\section{RESULTS}

In all, 155 subjects were invited to participate in this follow up study. This represented one third $(32.3 \%)$ of the original ACS cohort. Of these 155 subjects, four $(2.6 \%)$ were dead, 19 $(12.2 \%)$ were uncontactable by mail or telephone, and three (1.9\%) had relocated outside Auckland or were overseas. Only $32(20.6 \%)$ of those contacted were unable or declined or to participate: $10(6.4 \%)$ cited limited mobility, six $(3.9 \%)$ noted medical morbidity, and $16(10.3 \%)$ provided no reasons for non-participation. Therefore, 97 subjects formed the randomly selected 2 year follow up cohort.

While several subjects in the original ACS cohort underwent cataract surgery in both eyes, only one subject in the subgroup 2 years later has both eyes included in this study. Therefore, 98 eyes of 97 subjects $(62.6 \%$ of those subjects invited) were included. Visual acuity and spectacle refraction data were available for 476 subjects in the original ACS cohort and 97 subjects at 2 year follow up. Data for the subgroup of 97 subjects at 4 weeks were extracted and compared with the original cohort. There were no statistical differences between these groups in terms of refractive correction or BSCVA, confirming the subgroup to be representative of the original cohort 4 weeks after cataract surgery. Subject characteristics including age and ethnicity are shown in table 1 .

Table 1 Subject characteristics of the original cohort ( $n=488$ eyes of 480 subjects) and 2 year follow up subgroup ( $n=98$ eyes of 97 subjects) demonstrate that the subgroup is representative of the original cohort

\begin{tabular}{|c|c|c|c|}
\hline & Original cohort & Subgroup & p Value \\
\hline \multicolumn{4}{|l|}{ Age (years) } \\
\hline mean (SD) & $74.9(9.6)$ & $76.3(9.9)$ & NS \\
\hline range & $34.7-94.3$ & $47.1-96.7$ & \\
\hline Sex (female) & $62 \%$ & $66 \%$ & NS \\
\hline Right eye & $n=242(49.6 \%)$ & $n=47(48.0 \%)$ & NS \\
\hline Left eye & $\mathrm{n}=246(50.4 \%)$ & $\mathrm{n}=51 \quad(52.0 \%)$ & NS \\
\hline \multicolumn{4}{|l|}{ Ethnic origin } \\
\hline European & $n=346(72 \%)$ & $n=76$ (78.4\%) & NS \\
\hline Pacific Island & $n=48(10 \%)$ & $\mathrm{n}=8(8.2 \%)$ & \\
\hline Maori & $\mathrm{n}=38(8 \%)$ & $\mathrm{n}=6(6.2 \%)$ & \\
\hline Asian & $\mathrm{n}=33(7 \%)$ & $\mathrm{n}=3(3.1 \%)$ & \\
\hline Other & $\mathrm{n}=15(3 \%)$ & $\mathrm{n}=4(4.1 \%)$ & \\
\hline
\end{tabular}


Table 2 New ocular disease or ophthalmic procedures ( $n=10$ subjects) occurring in 98 eyes of 97 subjects within 2 years of cataract surgery

\begin{tabular}{lll}
\hline & Number $^{*}$ & Percentage $^{*}$ \\
\hline Nd:YAG posterior capsulotomy & 4 & 3.1 \\
Lid surgery & 2 & 2.0 \\
Trichiasis & 2 & 2.0 \\
Glaucoma & 1 & 1.0 \\
Membrane peel & 1 & 1.0 \\
NLD obstruction & 1 & 1.0 \\
PVD & 1 & 1.0 \\
Vitreal haemorrhage & 1 & 1.0 \\
Vitrectomy & 1 & 1.0 \\
\hline
\end{tabular}

NLD = nasolacrimal duct; PVD = posterior vitreal detachment *Some subjects were affected by more than one condition.

New systemic disease was self reported in 18 (18.4\%) subjects, most commonly CVA $(3.1 \%)$ and myocardial infarction, osteoporosis, and sciatica (each $2.1 \%$ ). There was one $(1.0 \%)$ new case each of asthma, inflammatory bowel disease, lung cancer, meningitis, Mycobacterium avium intracellulare infection, myelodysplasia, pacemaker insertion, peripheral vascular disease, pseudogout, thyroid disease, transient ischaemic attack, and type 2 diabetes mellitus.

New ocular diagnoses or additional ophthalmic procedures occurred in the operated eyes of $10(10.3 \%)$ subjects within 2 years of cataract surgery (table 2 ). Of fellow eyes, 60 $(61.2 \%)$ had undergone cataract surgery as predominantly public hospital procedures $(57.3 \%)$, and the majority of these $(43.4 \%)$ were performed before the ACS. Three fellow eyes $(3.1 \%)$ were on the waiting list for cataract surgery at the time of this review.

The unaided visual acuity (UAVA), best spectacle corrected visual acuity (BSCVA), and spectacle refraction were available both 4 weeks $(n=476)$ and 2 years after cataract surgery $(\mathrm{n}=98)$, and are shown in table 3 . At 2 years $66.3 \%$ of eyes achieved the New Zealand driver licence requirement $(6 / 12)$ unaided, whereas $52.0 \%$ obtained $6 / 9$ or better and $28.6 \%$ achieved $6 / 6$ or better UAVA. BSCVA was $6 /$ 12 or better in $93(94.9 \%)$ eyes. There were no significant alterations in mean astigmatism and mean spherical refractive error 2 years after surgery compared to the respective mean values 4 weeks postoperatively; however, a reduction in mean spherical equivalent over this time reached significance $(\mathrm{p}=0.04)$.

Forty three $(44.3 \%)$ of the 97 subjects were wearing distance spectacles 2 years after cataract surgery, 39 (40.2\%) having updated their spectacle prescription on at least one occasion between cataract surgery and follow up. One subject had subsequently lost their spectacles. Three subjects (3.1\%) stated they were advised not to update their spectacles, while one subject ( $1.0 \%)$ gave no reason. No subjects cited expense as a factor that prevented them from obtaining their postoperative spectacle correction. Of the remaining 54 subjects, $42(43.3 \%$ of total) used spectacles only for near and $12(12.4 \%$ of total) did not wear spectacles at all.

Slit lamp examination confirmed the posterior chamber IOL was well centred, relative to the dilated pupil, in $89.8 \%$ $(n=88)$ of eyes $(\leqslant 0.1 \mathrm{~mm})$. Decentration of the remaining 10 lenses, as measured by Scheimpflug photography, was generally less than $0.5 \mathrm{~mm}$ (range $0.2-1.2 \mathrm{~mm}$ ). No pseudophakodonesis was identified. Routine phacoemulsification had been performed in $98.0 \%$ of procedures. The AcrySof MA60BM (Alcon Laboratories) foldable acrylic lens was the most frequently used IOL $(95.0 \%)$. The remaining IOLs were the MC50BD (Alcon Laboratories) single piece PMMA $(2.0 \%)$, used in one case each of primary extracapsular cataract extraction (ECCE) and phacoemulsification conversion to ECCE, the 911A (Pharmacia and Upjohn) foldable silicone $(2.0 \%)$ and $812 \mathrm{C}$ (Pharmacia and Upjohn) single piece PMMA (1.0\%) lenses.

While $20(20.4 \%)$ eyes exhibited posterior capsule opacification (PCO), all cases were visually insignificant bar three (3.1\%) of these eyes that had previously undergone Nd:YAG posterior capsulotomy. Subjects who sustained intraoperative posterior capsule rupture were excluded from these analyses. The PCO rate in the contralateral eyes with IOL implants $(\mathrm{n}=60)$ was more than double that in the study group at $46.7 \%$. These surgeries, however, had been performed at variable times before the ipsilateral surgery in the ACS and details of IOL type were not available to the researchers. Similarly, most of these cases of contralateral PCO were mild and visually insignificant, but the contralateral eyes exhibited a higher rate of Nd:YAG posterior capsulotomy (10.0\%).

Visually significant findings on fundal examination are summarised in table 4 . The mean IOP measured 4 weeks after cataract surgery was 12.9 (3.2) $\mathrm{mm} \mathrm{Hg}$, and this remained low at 12.8 (3.3) $\mathrm{mm} \mathrm{Hg}$ in the same subgroup $(\mathrm{n}=98$ eyes $) 2$ years postoperatively.

Ten $(10.3 \%)$ subjects required referral to either a general practitioner $(2.1 \%)$ for systemic review or an ophthalmologist (8.2\%) for ongoing review and management of ocular disease identified in the operated eye at the time of examination. The latter comprised retinal pathology $(4.1 \%)$, suspected glaucoma $(3.1 \%)$, and referral for contralateral cataract surgery (1.0\%).

Orbscan II elevation topography maps were satisfactory for qualitative and quantitative analyses in 91 (92.9\%) of the eyes examined preoperatively and at 1 month and 2 years following phacoemulsification. Seven eyes were excluded from topographical analysis because of either incomplete

Table 3 Visual acuity and spectacle refraction at 4 weeks and 2 years after cataract surgery in the Auckland Cataract Study 2 year follow up subgroup ( $n=98$ eyes of 97 subjects)

\begin{tabular}{|c|c|c|c|c|}
\hline & & $\begin{array}{l}\text { Subgroup at } 4 \text { weeks } \\
(n=98)\end{array}$ & $\begin{array}{l}\text { Subgroup at } 2 \text { years } \\
(n=98)\end{array}$ & p Value \\
\hline UAVA & $\begin{array}{l}\text { mean } \log M A R(S D) \\
\text { range }\end{array}$ & $\begin{array}{l}0.3(0.3) \\
-0.1 \text { to } 1.0\end{array}$ & $\begin{array}{l}0.3(0.3) \\
-0.1 \text { to } 1.0\end{array}$ & 0.98 \\
\hline BSCVA & $\begin{array}{l}\text { mean } \log M A R(S D) \\
\text { range }\end{array}$ & $\begin{array}{l}0.1(0.2) \\
-0.1 \text { to } 1.0\end{array}$ & $\begin{array}{l}0.2(0.2) \\
-0.1 \text { to } 0.6\end{array}$ & $<0.0001$ \\
\hline $\begin{array}{l}\text { Spherical } \\
\text { equivalent (D) }\end{array}$ & $\begin{array}{l}\text { mean }(S D) \\
\text { range }\end{array}$ & $\begin{array}{l}-0.59(1.07) \\
-4.13 \text { to }+2.38\end{array}$ & $\begin{array}{l}-0.37(1.01) \\
-3.25 \text { to }+2.87\end{array}$ & 0.04 \\
\hline Astigmatism (D) & $\begin{array}{l}\text { mean }(S D) \\
\text { range }\end{array}$ & $\begin{array}{l}-1.14(0.77) \\
-4.50 \text { to } 0.00\end{array}$ & $\begin{array}{l}-1.07(0.70) \\
-4.00 \text { to } 0.00\end{array}$ & 0.34 \\
\hline
\end{tabular}

$\mathrm{UAVA}=$ unaided visual acuity; $\mathrm{BSCVA}=$ best spectacle corrected visual acuity; $\log M A R=\log$ minimum angle of resolution; $\log M A R-0.1$ corresponds to $6 / 4.8, \log$ MAR 0.1 to $6 / 7.5, \log$ MAR 0.2 to $6 / 9, \log$ MAR 0.3 to $6 /$ $12, \log$ MAR 0.6 to $6 / 24$ and $\log$ MAR 1.0 to $6 / 60$ Snellen equivalent; $D=$ dioptre. 


\begin{tabular}{|c|c|c|c|}
\hline & & Number & Percentage \\
\hline Conjunctiva & Pterygium onto cornea & 5 & 5.1 \\
\hline Cornea & Band keratopathy & 1 & 1.0 \\
\hline \multirow[t]{3}{*}{ PCO } & All grades & 20 & 20.4 \\
\hline & Currently visually significant & 0 & 0.0 \\
\hline & Previous $\mathrm{Nd}$ :YAG posterior capsulotomy & 3 & 3.1 \\
\hline \multirow[t]{4}{*}{ Macula } & AMD & 29 & 29.6 \\
\hline & Epiretinal membrane & 1 & 1.0 \\
\hline & BRVO & 1 & 1.0 \\
\hline & CRVO & 1 & 1.0 \\
\hline Optic nerve & Pathological cupping \pm pallor & 8 & 8.2 \\
\hline \multirow[t]{5}{*}{ Other } & Chorioretinal atrophy/scar (peripheral) & 4 & 4.1 \\
\hline & Extensive PRP & 1 & 1.0 \\
\hline & RPE detachment & 1 & 1.0 \\
\hline & Subretinal fibrosis & 1 & 1.0 \\
\hline & Vitreal haemorrhage & 1 & 1.0 \\
\hline
\end{tabular}

map patterns or inability to perform Orbscan II examination. Categorisation of the keratometric topographic maps is presented in table 5. Further subdivision of the preoperative bow tie (astigmatic) patterns highlighted that nine of 18 $(50 \%)$ symmetrical bow ties and five of $14(35.7 \%)$ asymmetric bow ties exhibited a "with the rule" distribution between $45^{\circ}$ and $135^{\circ}$.

Classification of axial keratometric maps on the first postoperative examination (1 month) was not statistically different from those obtained preoperatively. However, an increased number of irregular, inferior steepening, and symmetrical bow tie patterns was encountered. Axial topographic patterns 2 years after cataract surgery correlated highly (Spearman's correlation coefficient 0.9) with those recorded preoperatively.

Comparing the central corneal pachymetry, 1 month and 2 years post-surgery $(n=87)$, a decrease in mean thickness of 8.6 (SD 22.9) $\mu \mathrm{m}$ was demonstrated, with similar results at the incision site revealing a decrease of 8.7 (36.5) $\mu \mathrm{m}$ (table 6). However, there was no statistically significant difference between the change in pachymetry at either corneal region during this postoperative time period $(\mathrm{p}=0.484)$. In contrast, a significant change in pachymetry was identified comparing preoperative thickness and 2 year postoperative measurements, with central corneal thickness decreasing by $2.8(19.2) \mu \mathrm{m}$, whereas pachymetry at the incision site increased by $12.6(35.4) \mu \mathrm{m}(\mathrm{p}=0.0002)$. The overall change in peripheral corneal thickness was within plus or minus $40 \mu \mathrm{m}$ (range $-120-80 \mu \mathrm{m}$ ) in $78 \%$ of eyes examined $(n=91) 1$ month after surgery and $96.7 \% 2$ years after cataract surgery.

The subjective outcome questionnaire was completed by all subjects $(\mathrm{n}=97)$ at a mean time of 25.6 (1.7) months after cataract surgery, compared to $80.4 \%$ of the same subjects $(\mathrm{n}=78)$ a mean of $3.6(1.2)$ months postoperatively. Of the subjects who completed questionnaires, $79.5 \%$ were moderately to very satisfied with the initial level of vision achieved following cataract surgery, while $75.3 \%$ of subjects were equally satisfied 2 years postoperatively. Fewer subjects $(42.9 \%)$ were still driving at the 2 year follow up than initially post-surgery $(50.7 \%)$, this being because of other illness $(12.5 \%)$, problems with vision $(29.2 \%)$, and other unspecified reasons (58.3\%). (Further data from these questionnaires are the subject of a separate communication.)

Various iterative (stepwise, backward, and forward) multivariate regression models were produced to determine independent predictors of the change in visual acuity. New ocular disease explained most of the variance (34\%, $\mathrm{p}=0.001)$ followed by age $(11 \%, \mathrm{p}=0.01)$. No other parameter consistently reached the inclusion criteria.

\section{DISCUSSION}

The Auckland Cataract Study provided a representative assessment of the management of cataract in New Zealand, prospectively assessing 480 subjects undergoing cataract surgery in the public hospital system. The original ACS cohort was deemed representative of the NZ population. ${ }^{1}$ In the current study, random identification of one third of the

Table 5 Distribution of keratometric topographic maps after the classification by Rabinowitz et al and Bogan et ap

\begin{tabular}{|c|c|c|c|}
\hline \multirow[b]{2}{*}{ Topographic map } & \multicolumn{3}{|c|}{ Number of eyes (\%) } \\
\hline & $\begin{array}{l}\text { Preoperative } \\
(\mathrm{n}=91)\end{array}$ & $\begin{array}{l}1 \text { month postoperative } \\
(n=91)\end{array}$ & $\begin{array}{l}2 \text { years postoperative } \\
(\mathrm{n}=91)\end{array}$ \\
\hline $\begin{array}{l}\text { Round } \\
\text { Oval } \\
\text { Symmetric bow tie } \\
\text { Symmetric bow tie with skewed radial axes } \\
\text { Asymmetric bow tie with superior steepening } \\
\text { Asymmetric bow tie with inferior steepening } \\
\text { Asymmetric bow tie with skewed radial axes } \\
\text { Superior steepening } \\
\text { Inferior steepening } \\
\text { Irregular }\end{array}$ & $\begin{array}{l}26(28.5) \\
0(0.0) \\
15(16.5) \\
3(3.3) \\
3(3.3) \\
11(12.1) \\
0(0.0) \\
7(7.7) \\
6(6.6) \\
20(22.0)\end{array}$ & $\begin{array}{l}9(9.9) \\
0(0.0) \\
18(19.8) \\
6(6.6) \\
3(3.3) \\
5(5.5) \\
3(3.3) \\
7(7.7) \\
10(11.0) \\
30(32.9)\end{array}$ & $\begin{array}{l}18(19.8) \\
0(0.0) \\
17(18.7) \\
3(3.3) \\
6(6.6) \\
9(9.9) \\
0(0.0) \\
9(9.9) \\
6(6.6) \\
23(25.2)\end{array}$ \\
\hline
\end{tabular}


Table 6 Dynamic evaluation of the difference in corneal thickness comparing preoperative and 1 month postoperative values with pachymetry at 2 years. Proprietary software was used to subtract baseline pachymetry data from the pachymetry map obtained at the specified time. Two separate areas centred on the optical axis of the instrument $\left(12.57 \mathrm{~mm}^{2}\right)$ and at the incision site $\left(12.57 \mathrm{~mm}^{2}\right)$ were analysed, the overall peripheral corneal change was within plus or minus $40 \mu \mathrm{m}$ in $78 \%$ of eyes examined $(n=91) 1$ month after surgery and this percentage increased to $96.7 \%$ in 2 years

\begin{tabular}{|c|c|c|}
\hline \multirow[b]{3}{*}{ Corneal region analysed } & \multicolumn{2}{|c|}{ Change in pachymetry } \\
\hline & 2 years-1 month & 2 years-preop \\
\hline & Mean (SD)* & Mean (SD)* \\
\hline $\begin{array}{l}\text { Central corneal thickness }(\mu \mathrm{m}) \\
\text { (single area of } 12.57 \mathrm{~mm}^{2} \text { ) }\end{array}$ & $-8.6(22.9)$ & $-2.8(19.2)$ \\
\hline $\begin{array}{l}\text { Corneal thickness of a single } \\
\text { area }(\mu \mathrm{m})\left(12.57 \mathrm{~mm}^{2}\right) \text { centred } \\
\text { at the incision site }\end{array}$ & $-8.7(36.5)$ & $+12.6(35.4)$ \\
\hline $\begin{array}{l}\text { Difference between central } \\
\text { and peripheral thickness }\end{array}$ & $p=0.484$ & $p=0.0002$ \\
\hline
\end{tabular}

original study cohort with an invitation to participate in a 2 year assessment yielded a representative study population $(20.2 \%)$ of similar characteristics to the ACS group. Indeed, there were no significant differences in the population characteristics of the original cohort $(n=480)$ and the subgroup $(\mathrm{n}=97) 2$ years later (all $\mathrm{p}>0.05)$. Subjects were older and predominantly female, the slightly higher female preponderance at 2 years is probably attributable to the longer female life expectancy and consistent with international comparisons. ${ }^{12}$ Therefore, we believe this study population is a representative, random, $20 \%$ sample follow up of the ACS. However, one limitation of this prospective study was the inability to review approximately one third of the 155 subjects that were randomly identified, because of death, distance, and disability among other causes. Therefore, all possible outcomes after surgery, beneficial or otherwise, may not have been evaluated.

Two years following cataract surgery, approximately one in five subjects had developed new systemic co-morbidity. These were, most commonly, cerebrovascular and other cardiac diseases, a finding not dissimilar to the initial ACS given that more than one third had a history of such disease at the time of enrolment in the ACS. ${ }^{1}$ However, the magnitude of additional co-morbidity in the subgroup 2 years after cataract surgery is likely to be an underestimation, since $10 \%$ of the subjects initially invited to participate declined to do so secondary to poor mobility or unspecified medical comorbidity.

Factors influencing visual outcome following cataract surgery include pre-existing ocular disease such as diabetic retinopathy, level of education, age, and possibly the duration of phacoemulsification. ${ }^{13-15}$ The influence of increasing age on visual acuity achieved after cataract surgery has been previously documented. ${ }^{14}{ }^{16}{ }^{17}$ Importantly, investigators have demonstrated at least a fourfold reduction in likelihood of subjects aged 80 years and above achieving a postoperative BSCVA of 6/12 or better compared to subjects 10-20 years younger. ${ }^{14}$ In the current study, after controlling for potential confounding variables, multiple linear regression yielded age as the only significant, independent, non-ocular, predictor of change in visual acuity in the 2 year period studied. However, ocular disease involving the macula was the largest overall contributor to reduced visual acuity, with $30 \%$ of subjects demonstrating age related macular degenerative change. This is hardly surprising given the average age of the study population and is similar to that reported in a large series of subjects aged 60 years and older. ${ }^{14}$

Surgical outcomes following cataract surgery are frequently measured in terms of two moderately correlated parameters-namely, visual acuity and improvements in quality of life. ${ }^{11}$ While visual acuity is not a comprehensive measure of visual disability it is, none the less, a useful measure of visual outcome following cataract surgery. In a recent study, follow up of 460 subjects 3 months after cataract surgery yielded a mean BSCVA $\log$ MAR acuity of $0.2(0.2),{ }^{15}$ whereas, Kobayashi et al ${ }^{18}$ reported subjects achieving a mean BSCVA of $0.13 \log$ MAR units 1 year after phacoemulsification and 2 years later this remained stable at $0.148 \log$ MAR units. In the current study, comparing data for the 97 subjects at 4 weeks and 2 years after cataract surgery, revealed a stable mean UAVA, although the mean BSCVA had decreased by the equivalent of one Snellen line, to $6 / 9$, at 2 years $(\mathrm{p}<0.0001)$.

Modern phacoemulsification may enable postoperative best corrected Snellen visual acuity of $6 / 12$ or better in approximately $90 \%$ of eyes in general, and in $95 \%$ of eyes with no pre-existing ocular disease. ${ }^{15} 14171920$ However, there is little information pertaining to the longer term maintenance of this improved visual function. In this study $94.9 \%$ of subjects retained a BSCVA of 6/12 or better despite many eyes exhibiting pre-existing ocular disease. None the less, while this implies that $94.9 \%$ of subjects maintained sufficient BSCVA to retain a New Zealand driver licence, only $63.6 \%$ of subjects who have ever driven a vehicle $(\mathrm{n}=66)$ continued to do so, with $29.2 \%$ of subjects stating they no longer continued to drive owing to "problems" with vision. Overall, of the subjects who completed questionnaires, $79.5 \%$ were moderately to very satisfied with the initial level of vision achieved following cataract surgery and $75.3 \%$ of subjects were equally satisfied 2 years postoperatively.

Although 6/12 BSCVA is a relatively arbitrary measure used to classify functional visual outcome it has commonly been used to classify clinical outcomes, ${ }^{5021}$ but may not adequately reflect optimal surgical outcome as more subjects with visual acuity at, or better than, $6 / 12$ proceed to cataract surgery. While early intervention is an already established expectation, ${ }^{22}$ significant differences exist in thresholds for cataract surgery in the developed world. ${ }^{12}$ It is worth noting that lowering the threshold for cataract surgery has already been shown to dramatically affect the eligibility of subjects for such surgery. ${ }^{23-25}$ In New Zealand public hospitals, given the points based prioritisation process employed, subjects would generally be unlikely to proceed to cataract surgery in the public setting with a Snellen visual acuity better than 6/ 12 , unless there was additional clinical justification for doing so, such as glare from posterior subcapsular cataract or treatable retinal pathology. ${ }^{26}$

Previously, PCO was the leading cause of visual loss after cataract surgery. Meta-analysis estimates the incidence of visually significant PCO to affect $25 \%$ of subjects within 5 years of cataract surgery with PCIOL implantation. ${ }^{27}$ In the current study, the overall rate of PCO was $20.4 \%$, although only $3.1 \%$ of subjects had sufficiently dense PCO to require Nd:YAG posterior capsulotomy. Therefore, it may be concluded that the visually significant PCO rate in this study was low at $3.1 \%$, comparable to that quoted by other authors within 2 years of follow up. ${ }^{28}{ }^{29}$ However, it is impossible to make a valid comparison or extrapolation between the rates of PCO in the current study at 2 year follow up compared to 5 years in the meta-analysis of Schaumberg et al. ${ }^{27}$ 
The rate of development of PCO is dependent on several variables, including age and type of cataract, size of anterior capsulotomy, type and placement of PCIOL, and other surgical variables. ${ }^{27}{ }^{30-34}$ The relation between intraocular lens materials and percentage of PCO, 2 years after PCIOL implantation, was investigated by Ursell et al, ${ }^{35}$ who concluded acrylic lenses induced significantly less PCO (11.75\%) than did other biomaterials (greater than 33\%). This finding has been confirmed by other authors. ${ }^{28} 29313236$ Almost all eyes (95\%) in the current study had received AcrySof acrylic IOL implants and this may partly account for the low rate of PCO in the study eyes at 2 year follow up. ${ }^{35}$

New ocular pathology necessitating referral was diagnosed in $10.3 \%$ of subjects at the time of follow up. While one in 12 subjects required referral for ongoing ophthalmology review, if subjects referred for cataract surgery are excluded, this incidence drops to one in 14 subjects. While subjects were referred for clinical indications not directly attributable to previous cataract surgery, these findings tend to suggest subjects might benefit by being reviewed or screened over a period longer than the widely accepted 1 or 3 month postoperative review.

The time dependent analyses using the Orbscan II proprietary software may be applied to any of the topographical maps including keratometric, pachymetric, and elevation. The advantage of this approach is a direct appreciation of the global change of corneal parameters over time. Indeed, fourth dimensional analysis of corneal thickness still highlighted significant "thickening" at the site of incision 2 years after cataract surgery. Grupcheva et $a l^{8}$ highlighted the same phenomenon at the incision site 1 month following phacoemulsification and although this feature may be attributed to subclinical focal corneal oedema 1 month after surgery, at 2 years post surgery this may, theoretically, be the result of artefact caused by fibrosis or other optical effect related to the wound healing. ${ }^{8}$ In the Auckland Cataract Study, in a larger sample, Grupcheva et al demonstrated an increase in central corneal thickness of 7.41 (21.02) $\mu \mathrm{m}$ during the first 1 month postoperative period. In the current study, a decrease in mean central corneal thickness of 8.6 (22.9) $\mu \mathrm{m}$ was noted comparing the 1 month and 2 year data, with a similar decrease at the incision site. However, comparing the difference in mean pachymetry, preoperatively and 2 years post-surgery, central corneal thickness actually decreased by a small amount $(2.8(19.2) \mu \mathrm{m})$, whereas overall the measured pachymetry at the incision site increased by 12.6 (35.4) $\mu \mathrm{m}$. This suggests that there is a short term increase in pachymetry at the incision site over the initial 1 month postoperative period, followed by a reduction in this increased thickness during the subsequent 2 year period, but this does not return to the initial preoperative level.

In summary, this Auckland based population study illustrates that, despite significant medical co-morbidity, $94.9 \%$ of eyes in this elderly population maintained a BSCVA of $6 / 12$ or better 2 years after cataract surgery. With an increasing ageing population, there is a high demand for maintenance of the improved visual acuity following cataract surgery. In this respect, it will be interesting to review these subjects at later intervals following cataract surgery, in order to determine rates of progression of PCO, development of vision threatening ocular co-morbidities, and whether a satisfactory level of vision is maintained.

\section{ACKNOWLEDGEMENTS}

We thank Tasia Huckle, Alison O'Connor, Dr Jennifer Craig, Dr Tahira Malik, Dr Michael Fisk and the nursing, administrative and surgical staff of Auckland Hospital Ophthalmology Department and the University Department of Ophthalmology for their support with the original Auckland Cataract Study and this 2 year follow up. We particularly wish to acknowledge Greg Gamble for his assistance with the statistical analyses.

\section{Authors' affiliations}

A M Thompson, N Sachdev, T Wong, A F Riley, C N Grupcheva,

C N McGhee, Department of Ophthalmology, University of Auckland, Auckland, New Zealand

C N Grupcheva, Specialised Ophthalmic Hospital, Varna, Bulgaria

The authors have no proprietary, financial, or commercial interest in any of the companies or products mentioned in this paper.

\section{REFERENCES}

1 Riley AF, Malik TY, Grupcheva CN, et al. The Auckland Cataract Study: comorbidity, surgical techniques, and clinical outcomes in a public hospital service, Br J Ophthalmol 2002:86:185-90.

2 Riley AF, Grupcheva CN, Malik TY, et al. The Auckland Cataract Study: demographic, corneal topographic and ocular biometric parameters. Clin Exp Ophthalmol 2001;29:381-6.

3 Lyhne N, Krogsager J, Corydon L, et al. One year follow-up of astigmatism after $4.0 \mathrm{~mm}$ temporal clear corneal and superior scleral incisions. J Cataract Refract Surg 2000;26:83-7.

4 Monestam E, Wachtmeister L. Dissatisfaction with cataract surgery in relation to visual results in a population-based study in Sweden. J Cataract Refract Surg 1999;25:1127-34.

5 Powe NR, Schein OD, Gieser SC, et al. Synthesis of the literature on visual acuity and complications following cataract extraction with intraocular lens implantation. Arch Ophthalmol 1994;112:239-52.

6 Rabinowitz YS, Yang H, Brickman Y, et al. Videokeratography database of normal human corneas. Br J Ophthalmol 1996;80:610-6.

7 Bogan SJ, Waring GO, Ibrahim O, et al. Classification of normal corneal topography based on computer-assisted videokeratography. Arch Ophthalmol 1990;108:945-9.

8 Grupcheva CN, Riley AF, Craig JP, et al. Analyzing small-incision cataract surgery by Orbscan II fourth-dimensional pachymetry mapping. J Cataract Refract Surg 2002;28:2153-8.

9 Zaczek A, Zetterstrom C. Posterior capsule opacification after phacoemulsification in patients with diabetes mellitis. J Cataract Refract Surg 1999:25:233-7.

10 Tetz MR, Auffarth GU, Sperker M, et al. Photographic image analysis system of posterior capsule opacification. J Cataract Refract Surg 1997;23:1515-20.

11 Steinberg EP, Tielsch JM, Schein OD, et al. The VF-14-an index of functional impairment in patients with cataract. Arch Ophthalmol 1994;112:630-8.

12 Norregaard JC, Bernth-Petersen P, Alonso J, et al. Variation in indications for cataract surgery in the United States, Denmark, Canada, and Spain: results from the International Cataract Surgery Outcomes Study. Br J Ophthalmol 1998;82:1107-11.

13 Somaiya MD, Burns JD, Mintz R, et al. Factors affecting visual outcomes after small-incision phacoemulsification in diabetic patients. J Cataract Refract Surg 2002;28:1364-71

14 Westcott MC, Tuft SJ, Minassian DC. Effect of age on visual outcome following cataract extraction. Br J Ophthalmol 2000;84:1380-2.

15 Saw SM, Tseng P, Chan WK, et al. Visual function and outcomes after cataract surgery in a Singapore population. J Cataract Refract Surg 2002;28:445-53.

16 Norregaard JC, Hindsberger C, Alonso J, et al. Visual outcomes of cataract surgery in the United States, Canada, Denmark, and Spain. Report from the International Cataract Surgery Outcomes Study. Arch Ophthalmol 1998;116:1095-100

17 lonides A, Minassian DC, Tuft SJ. Visual outcome following posterior capsule rupture during cataract surgery. $\mathrm{Br} J$ Ophthalmol 2001;85:222-4.

18 Kobayashi $\mathrm{H}$, Ikeda $\mathrm{H}$, Imamura $\mathrm{S}$, et al. Clinical assessment of long-term safety and efficacy of a widely implanted polyacrylic intraocular lens material. Am J Ophthalmol 2000;130:310-21.

19 Murphy C, Tuft SJ, Minassian DC. Refractive error and visual outcome after cataract extraction. J Cataract Refract Surg 2002;28:62-6.

20 Desai P, Minassian DC, Reidy A. National cataract surgery survey 1997-8: a report of the results of the clinical outcomes. Br J Ophthalmol 1999;83:1336-40.

21 Minassian DC, Reidy A, Desai $P$, et al. The deficit in cataract surgery in England and Wales and the escalating problem of visual impairment: epidemiological modelling of the population dynamics of cataract. Br J Ophthalmol 2000;84:4-8.

22 Allan B. Intraocular lens implants. Have come a long way, but the advances are not yet available to all. BMJ 2000;320:73-4

23 Taylor HR. Cataract: how much surgery do we have to do? Br J Ophthalmol 2000;84:1-2

24 McCarty CA, Keeffe JE, Taylor HR. The need for cataract surgery: projections based on lens opacity, visual acuity, and personal concern. Br J Ophthalmol 1999:83:62-5

25 Setty $R$, Bosanquet R, Harle J. Changing thresholds for cataract surgery. Br J Ophthalmol 2000;84:1439.

26 Riley AF, Grupcheva CN, Malik TY, et al. The waiting game: natural history of a cataract waiting list in New Zealand. Clin Exp Ophthalmol 2001;29:376-80.

27 Schaumberg DA, Dana MR, Christen WG, et al. A systematic overview of the incidence of posterior capsule opacification. Ophthalmology 1998; 105: 1213-21. 
28 Scaramuzza A, Fernando GT Crayford BB. Posterior capsule opacification and lens epithelial cell layer formation: Hydroview hydrogel versus AcrySof acrylic intraocular lenses. J Cataract Refract Surg 2001;27:1047-54.

29 Olsen G, Olson RJ. Update on a long-term, prospective study of capsulotomy and retinal detachment rates affer cataract surgery. I Cataract Refract Surg 2000;26:1017-21.

30 Hollick EJ, Spalton DJ, Meacock WR. The effect of capsulorhexis size on posterior capsular opacification: one-year results of a randomised prospective trial. Am J Ophthalmol 1999;128:271-79.

31 Hollick EJ, Spalton DJ, Ursell PG, et al. The effect of polymethylmethacrylate, silicone, and polyacrylic intraocular lenses on posterior capsular opacification 3 years after cataract surgery. Ophthalmology 1999; 106:49-55
32 Hayashi K, Hayashi $\mathrm{H}$, Nakao F, et al. Changes in posterior capsule opacification after poly(methyl methacrylate), silicone, and acrylic intraocular lens implantation. J Cataract Refract Surg 2001;27:817-24

33 Schmidbaver JM, Vargas LG, Apple DJ, et al. Evaluation of neodymium:yttrium-aluminium-garnet capsulotomies in eyes implanted with AcrySof intraocular lenses. Ophthalmology 2002;109:1421-6.

34 Ravalico G, Tognetto D, Palomba M, et al. Capsulorhexis size and posterior capsule opacification. $J$ Cataract Refract Surg 1996;22:98-103.

35 Ursell PG, Spalton DJ, Pande MV, et al. Relationship between intraocular lens biomaterials and posterior capsule opacification. J Cataract Refract Surg 1998;24:352-60

36 Kucuksumer $Y$, Bayraktar S, Sahin S, et al. Posterior capsule opacification 3 years after implantation of an AcrySof and a MemoryLens in fellow eyes. J Cataract Refract Surg 2000;26:1176-82. 